\title{
Resuspension and Lateral Transport of Seafloor Sediment Contaminated with Artificial Radionuclides Derived from the Fukushima Daiichi Nuclear Power Plant Accident
}

\author{
Japan Agency for Marine-Earth Science and Technology, Makio Honda \\ Japan Atomic Energy Agency (present: The University of Tokyo), Shigeyoshi Otosaka
}

\begin{abstract}
In July 2011, settling particle collectors (sediment traps) were deployed on the continental slope located to the southeast of the Fukushima Daiichi Nuclear Power Plant (FDNPP) to assess quantitatively how the particulate radiocesium released in the FDNPP Accident was transported in the ocean. For the subsequent three years, measurements were conducted on the collected particulate radiocesium. Radiocesium from the accident was still detected in the early summer of 2014, and an increasing trend was observed every autumn. The collected particles mostly consisted of lithogenic materials. The collected radiocesium flux was much larger than the radiocesium suspected based on the concentration of dissolved radiocesium in the upper water column. These findings suggested the resuspension of seafloor sediment contaminated with radiocesium and its lateral transport to the continental slope. The observed increase in both the concentration and flux of radiocesium every autumn was presumed to be a result of the increased resuspension and lateral transport of coastal seafloor sediment caused by approaching and passing typhoons.
\end{abstract}

KEYWORDS: Fukushima Daiichi Nuclear Power Plant, radiocesium, particulate radiocesium, sediment trap, settling particle, seafloor sediment, resuspension, lateral transport, typhoon

\section{Introduction}

On March 11, 2011, the 2011 Tohoku-oki earthquake, which had a magnitude of 9.0, triggered a major tsunami off the Pacific coast of Tohoku. The ensuing devastation led to the shutdown of cooling systems at the Fukushima Daiichi Nuclear Power Plant (FDNPP), which is operated by the Tokyo Electric Power Company (TEPCO). A large amount of artificial radionuclides was released during subsequent incidents, including the venting, hydrogen explosion, leakage of externally supplied cooling water, and intentional discharge. The FDNPP

DOI : 10.15669/fukushimainsights.Vol.2.82

(C) 2021 Atomic Energy Society of Japan. All rights reserved.

Originally published in Journal of the Atomic Energy Society of Japan (ISSN 1882-2606), Vol. 58, No. 4, p. 225-228 (2016)

in Japanese. (Japanese version accepted: January 9, 2016) 
Accident was assigned the maximum level of 7 on the International Nuclear Event Scale (INES), which is the same level as that assigned to the Chernobyl NPP Accident that occurred on April 26, 1986. Radiocesium (i.e., cesium-137 ( $\left.{ }^{137} \mathrm{Cs}\right)$ ) accounted for the main portion of the released artificial radionuclides. According to the latest estimates ${ }^{1)}, 3$ to $6 \mathrm{PBq}$ of the total 15 to $20 \mathrm{PBq}\left(10^{15} \mathrm{~Bq}\right)$ of released radiocesium was deposited on land, $3.6 \pm 0.7 \mathrm{PBq}$ was directly discharged into the ocean, and the other 12 to $15 \mathrm{PBq}$ was transported to the ocean through the atmosphere. Almost $80 \%$ of the released radiocesium ended up in the ocean.

A survey was begun in the immediate aftermath of the accident to monitor the migration, dispersion, and distribution of the radiocesium released into the ocean. Measurements of radiocesium have been conducted on seawater, marine organisms from lower to higher trophic levels, suspended/settling particles, and seafloor sediment. The dissolved radiocesium that was released directly into the ocean migrated and dispersed eastward along the Kuroshio extension. Part of this radiocesium reportedly reached the West Coast of the United States in $2014^{2)}$, while another part gradually infiltrated the ocean interior through convective overturning during winter and the formation of an intermediate water ${ }^{3)}$.

Part of the radiocesium released into the ocean was captured by marine organisms, suspended/settling particles, and seafloor sediment. The behavior of the radiocesium collected by settling particles has been studied using time-series sediment traps ${ }^{4)}$.

A sediment trap is a type of settling particle collector that is moored undersea in a fixed position using mooring ropes, a float, an anchor, and a releaser, the latter of which connects the mooring system to the anchor during the sampling period and then releases the anchor when the mooring system is recovered. A time-series sediment trap automatically replaces multiple sampling cups at preset intervals of between a few days and about a month. Time-series sediment traps had been moored at two pelagic zones located in the western North Pacific when the FDNPP Accident took place. They were located at a horizontal distance of about 2,000 km and 1,000 km from the FDNPP (see Observation Sites K2 and S1 in Figure 1). These traps were recovered later and the radiocesium in the collected time-series settling particles was measured. The measurements revealed that radiocesium derived from

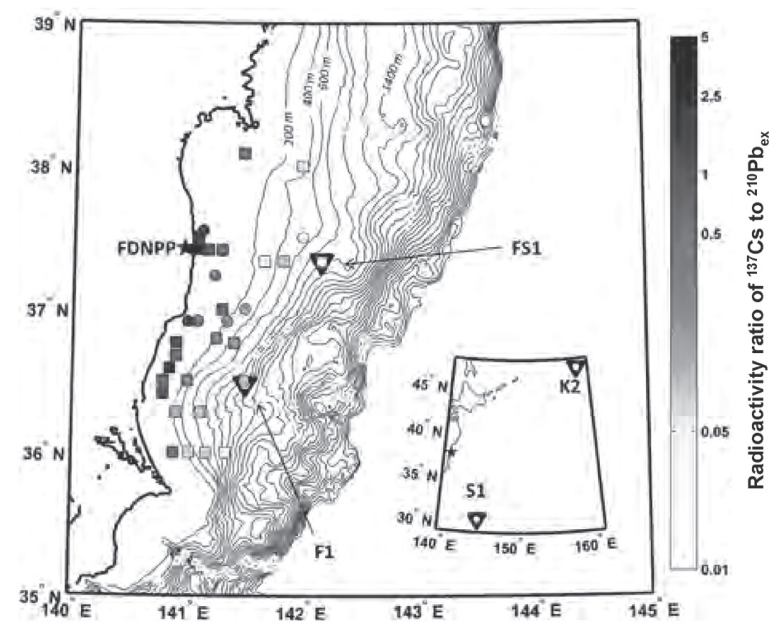

Figure 1 Mooring locations of time-series sediment traps in the western Northern Pacific (open inverted triangles). Depth contours are every $200 \mathrm{~m}$. The background value presents the ratio of radioactivity for radiocesium $\left({ }^{137} \mathrm{Cs}\right)$ to the excess radiolead $\left({ }^{210} \mathrm{~Pb}_{\mathrm{ex}}\right)$ on the top layer of the seafloor sediment (modified version of Figure 1 from Reference Document \#6). 
the FDNPP Accident had already been carried vertically to a depth of about 5,000 m at both sites about one month after the accident ${ }^{5}$. After the accident, time-series sediment traps were also deployed in semi-pelagic zones (Observation Site F1) to observe the particulate radiocesium. This commentary provides a detailed explanation of the results of the survey conducted by the authors and their colleagues (Reference Document \#6) at Observation Site $\mathrm{F} 1$, which is located $115 \mathrm{~km}$ to the southeast of the FDNPP. The measurement of radiocesium in settling particles implies the resuspension of seafloor sediment contaminated with radiocesium from the accident and its subsequent lateral underwater transport toward the continental slope.

\section{Observation Research of Settling Particles by Using the Sediment Traps at F1}

\section{Observation Site and Results from Time-Series Sediment Traps}

The observations were conducted using time-series sediment traps over the continental slope (depth: 1,300 m) at Observation Site F1 $\left(36^{\circ} 28^{\prime}\right.$ N, $141^{\circ} 28^{\prime}$ E). Settling particles were collected over a three-year period from July 2011 (i.e., about four months after the FDNPP Accident) until June 2014 at depths of $500 \mathrm{~m}$ and 1,000 m. The traps were deployed and recovered roughly once a year and the time-series settling particles were collected at intervals of between 16 and 36 days. The collected particles were taken back to an onshore laboratory to measure the radiocesium $\left({ }^{134} \mathrm{Cs}\right.$ and $\left.{ }^{137} \mathrm{Cs}\right)$ by gamma-ray spectrometry with a germanium semiconductor detector. In almost all of the periods, ${ }^{134} \mathrm{Cs}$ was detected in the collected settling particles. Before the accident, ${ }^{134} \mathrm{Cs}$ was almost absent in the environment. Furthermore, the radioactivity ratio of ${ }^{134} \mathrm{Cs}$ to ${ }^{137} \mathrm{Cs}\left({ }^{134} \mathrm{Cs} /{ }^{137} \mathrm{Cs}\right)$ was almost 1 after radioactive decay correction to March 11, 2011. The ${ }^{134} \mathrm{Cs} /{ }^{137} \mathrm{Cs}$ that was released due to the accident was reportedly 1. Given these facts, it is clear that the radiocesium detected in the settling particles originated from the FDNPP Accident.

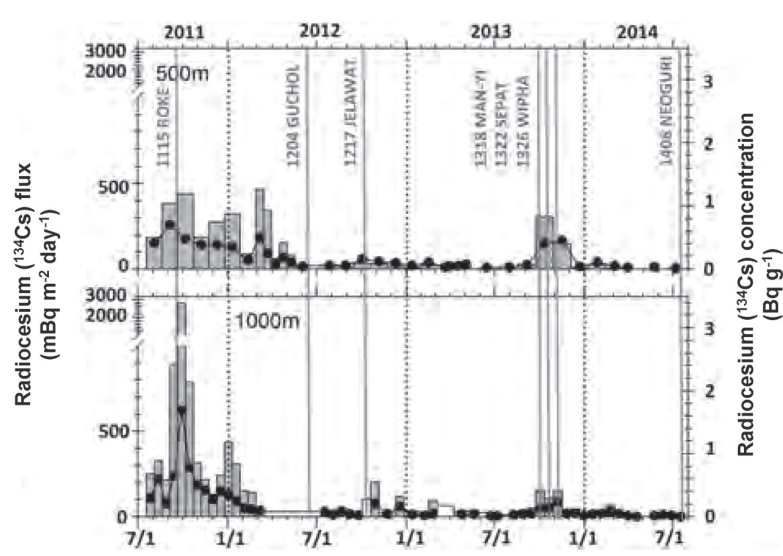

Figure 2 Radiocesium $\left({ }^{134} \mathrm{Cs}\right.$ ) flux (bar chart) and concentration (black circles) at $500 \mathrm{~m}$ (top) and 1,000 $\mathrm{m}$ (bottom).

White bars represent values interpolated from the preceding and following flux levels. Vertical solid lines represent typhoons that passed within $100 \mathrm{~km}$ of the FDNPP during the observation period (modified version of Figure 2 from Reference Document \#6). 
During Mooring Period I (July 2011 to July 2012), an increase in the ${ }^{134}$ Cs flux (total radioactivity of particulate ${ }^{134} \mathrm{Cs}$ per square meter per day: $\mathrm{mBq} \mathrm{m}{ }^{-2}$ day ${ }^{-1}$ ) was noted at $500 \mathrm{~m}$ during the following periods: September to October 2011, December 2011 to January 2012, and February to March 2012 (Figure 2). The same seasonal change was observed at 1,000 m, except that the annual total of the ${ }^{134} \mathrm{Cs}$ flux was about 1.5 times greater than that of the level observed at $500 \mathrm{~m}$. The highest ${ }^{134} \mathrm{Cs}$ flux to date (ca. $2,800 \mathrm{mBq} \mathrm{m}^{-2}$ day ${ }^{-1}$ ) was observed at a depth of 1,000 m between September and October 2011 ${ }^{4}$. During Mooring Period II (July 2012 to July 2013), the total ${ }^{134}$ Cs flux was roughly one fifth to one sixth that of Period I. A somewhat high level of ${ }^{134} \mathrm{Cs}$ flux was noted in around October at 1,000 m. During Mooring Period III (July 2013 to July 2014), a high flux that was comparable to that of Period I was observed between September and October 2013 at $500 \mathrm{~m}$. An increase in both the ${ }^{134} \mathrm{Cs}$ flux and the concentration was noted during the same period at $1,000 \mathrm{~m}$. The fact that ${ }^{134} \mathrm{Cs}$ was detected in all of the samples from the site indicated that the transport of the particulate radiocesium produced in the FDNPP Accident continued at the site even after three years.

\section{Estimated Origin of Particulate Radiocesium}

At $500 \mathrm{~m}(1,000 \mathrm{~m})$, the annual total ${ }^{134} \mathrm{Cs}$ flux $\left(\approx{ }^{137} \mathrm{Cs}\right)$ during Periods I, II, and III amounted to 98 (143), 11 (30), and 46 (33) $\mathrm{Bq} \mathrm{m}^{-2} \mathrm{yr}^{-1}$, respectively. In his earlier paper ${ }^{7)}$, one of the authors (Otosaka) proposed using the following equation to estimate the particulate ${ }^{134}$ Cs flux.

$$
\mathrm{FCs}=\mathrm{Cw} \times \mathrm{K}^{*} \times \mathrm{Fv}
$$

where $\mathrm{Cw}$ denotes the ${ }^{134} \mathrm{Cs}$ concentration $\left(\mathrm{Bq} \mathrm{L}^{-1}\right)$ of seawater at the surface of the observation point (depth: $0 \mathrm{~m}$ to $50 \mathrm{~m}$ ), $\mathrm{K}^{*}$ denotes the ratio of the ${ }^{134} \mathrm{Cs}$ concentration in suspended particles to the ${ }^{134} \mathrm{Cs}$ concentration in ambient water (known as the "partition coefficient"; the value in this case being $3.5 \mathrm{~L} \mathrm{~g}^{-1}$ ), and Fv denotes the total particle mass flux $\left(\mathrm{mg} \mathrm{m}^{-2}\right.$ day $^{-1}$ ). Using this equation, the annual total ${ }^{134} \mathrm{Cs}$ flux was estimated to be roughly $3.3 \mathrm{~Bq} \mathrm{~m}^{-2} \mathrm{yr}^{-1}$ at Observation Site F1 by applying the overall average total mass flux at 1,000 m during the observation period $\left(740 \mathrm{mg} \mathrm{m}^{-2}\right.$ day $^{-1}$ ) as well as the ${ }^{134} \mathrm{Cs}$ concentration in the surface seawater near F1 (average concentration at a depth of between 0 and $100 \mathrm{~m}$ in May 2012 and May 2013: ca. $\left.3.5 \times 10^{-3} \mathrm{~Bq} \mathrm{~L}^{-1}\right)^{6}$. The estimated value is lower by an order of magnitude than the annual total ${ }^{134} \mathrm{Cs}$ flux observed during the three years at $500 \mathrm{~m}$ and $1,000 \mathrm{~m}$ (11-98 $\left.\mathrm{Bq} \mathrm{m}^{-2} \mathrm{yr}^{-1}\right)$. This finding demonstrates that the radiocesium adsorbed on the settling particles that sank from the surface above Observation Site F1 alone cannot account for the particulate radiocesium collected by the sediment traps.

The total mass flux during Mooring Period I (July 2011 to July 2012) was around $770 \mathrm{mg} \mathrm{m}^{-2}$ day $^{-1}$ at $500 \mathrm{~m}$ and around $980 \mathrm{mg} \mathrm{m}^{-2}$ day $^{-1}$ at $1,000 \mathrm{~m}$ (Figure 3). These total mass fluxes were much higher than the total mass flux observed at around 5,000 $\mathrm{m}$ at Observation Sites K2 and S1, which are located in pelagic zones (K2: ca. $160 \mathrm{mg} \mathrm{m}^{-2}$ day $^{-1}$; S1: ca. $45 \mathrm{mg} \mathrm{m}^{-2}$ day $^{-1}$ ). In sharp contrast to the settling particles at $\mathrm{K} 2$ and S1, which mainly consisted of biogenic materials (biogenic opal at K2 and calcium carbonate at S1), more than half of the settling particles at F1 consisted of lithogenic materials. The seasonal change in the particles observed at F1 differed significantly from the typical seasonal change caused by lower trophic biological (zoo/phyto plankton) activity, which is high in spring and summer but low in winter. These conditions suggested that particles rich in lithogenic materials were transported laterally before they were collected by the time-series sediment traps. 


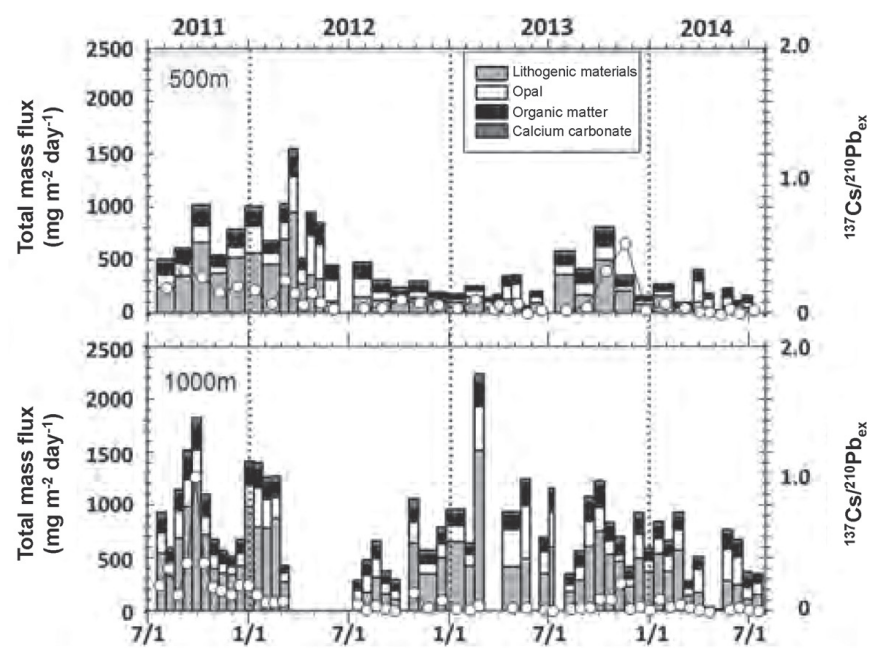

Figure 3 Flux of main components (bar chart) and radioactivity ratio of radiocesium $\left({ }^{137} \mathrm{Cs}\right)$ to excess radiolead $\left({ }^{210} \mathrm{~Pb}_{\mathrm{ex}}\right)\left({ }^{137} \mathrm{Cs} /{ }^{210} \mathrm{~Pb}_{\mathrm{ex}}\right.$ : white circles) at $500 \mathrm{~m}$ (top) and $1,000 \mathrm{~m}$ (bottom) (modified version of Figure 2 from Reference Document \#6).

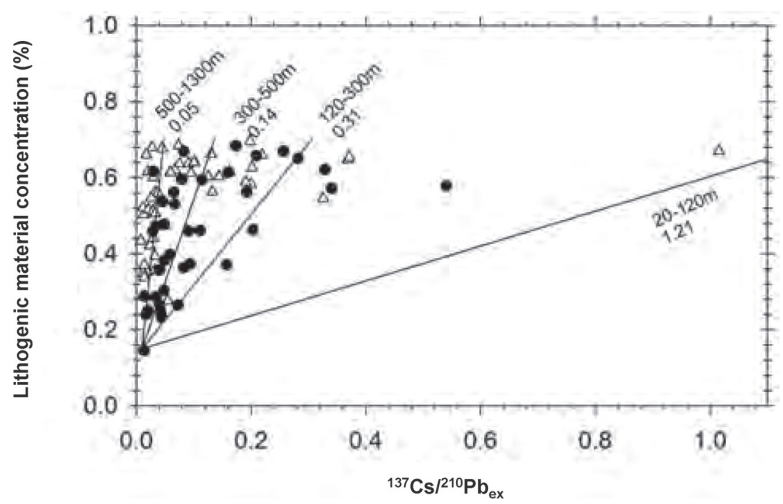

Figure 4 Relationship between ${ }^{137} \mathrm{Cs}^{210} \mathrm{~Pb}_{\mathrm{ex}}$ and the concentration of lithogenic materials for settling particles (black circles and white triangles correspond to traps at $500 \mathrm{~m}$ and 1,000 m, respectively). Straight lines in the figure indicate the relationship between ${ }^{137} \mathrm{Cs} /{ }^{210} \mathrm{~Pb}_{\mathrm{ex}}$ and the lithogenic material concentration in the seafloor sediment in the environs of the FDNPP at each depth (modified version of Figure S2 from Reference Document \#6).

In the next step, the radioactivity ratio of ${ }^{137} \mathrm{Cs}$ to ${ }^{210} \mathrm{~Pb}_{\mathrm{ex}}\left({ }^{137} \mathrm{Cs} /{ }^{210} \mathrm{~Pb}_{\mathrm{ex}}\right)$ was calculated (Figure 3). Unlike authigenic radiolead, ${ }^{210} \mathrm{~Pb}_{\mathrm{ex}}$ is radiolead that is not generated from the radioactive decay of ${ }^{226} \mathrm{Ra}$ in settling particles (excess radiolead $\left({ }^{210} \mathrm{~Pb}\right.$ ex $)$ : the total amount of ${ }^{210} \mathrm{~Pb}$ that is supposedly supplied from the atmosphere to the surface area above F1 and the ${ }^{210} \mathrm{~Pb}$ that is presumably generated in the water column from the surface area above F1 down to the target distance (500 $\mathrm{m}$ or 1,000 $\mathrm{m}$ in this study) and becomes adsorbed on the settling particles). The calculated ${ }^{137} \mathrm{Cs}^{210} \mathrm{~Pb}_{\text {ex }}$ ranged from 0.02 to 1.0 , which are similar to the figures observed for the seafloor sediment in the waters extending from the shallow waters in the environs of the FDNPP to a depth of about 1,300 m near F1 (Figure 1). This finding supports the explanation that radiologically contaminated seafloor sediment was resuspended, laterally transported and then collected by the sediment traps at $500 \mathrm{~m}$ and 1,000 $\mathrm{m}$ at F1. 
Subsequently, the origin of the captured seafloor sediment was estimated by comparing the relationship between ${ }^{137} \mathrm{Cs} /{ }^{210} \mathrm{~Pb}$ ex and the lithogenic material concentration of the settling particles with the relationship for the seafloor sediment in the environs of the FDNPP at the respective depth levels (Figure 4). This comparison suggested that a large part of the collected particles might be resuspended seafloor sediment at a depth of over $120 \mathrm{~m}$. The ${ }^{137} \mathrm{Cs} /{ }^{210} \mathrm{~Pb}_{\text {ex }}$ in excess of 0.3 is most likely the result of a resuspension of the seafloor sediment in shallower waters (120 m beneath the surface). The settling particles collected each autumn presented a high ${ }^{137} \mathrm{Cs} /{ }^{210} \mathrm{~Pb}_{\mathrm{ex}}$ and a high concentration of lithogenic materials (Figure 3). During this season, typhoons passed within $100 \mathrm{~km}$ of the FDNPP. Notably, the amount of ${ }^{137} \mathrm{Cs}$, the ${ }^{137} \mathrm{Cs} /{ }^{210} \mathrm{~Pb}_{\mathrm{ex}}$, and the lithogenic material concentrations were high in autumn 2013 when three typhoons passed through the area (Figure 2). These findings indicated the tendency for the heavy weather caused by typhoons to result in the resuspension of the seafloor sediment from shallower waters and the lateral transport to the continental slope where F1 is located.

Resuspension and lateral transport toward the continental slope have also been reported for seafloor sediment located about $100 \mathrm{~km}$ to the east of the FDNPP (Observation Site FS1 in Figure 1) based on an observation conducted using a sediment trap at a depth of $875 \mathrm{~m}^{7}$. The total mass flux at FS1 was about half and the radiocesium flux was about $10 \%$ compared to the levels registered at $\mathrm{F} 1{ }^{6}$. . Presumably, the lateral transport of the seafloor sediment from off the coast of the FDNPP was predominantly toward the southeast considering the average direction of the flow of seawater ${ }^{1)}$ and the distribution of the radiocesium concentration in the seafloor sediment ${ }^{8}$.

\section{Residence Time or Attenuation Time of Radiocesium in Seafloor Sediment in the Environs of the FDNPP}

Most of the radiocesium released into the ocean from the FDNPP was suspected to have been dissolved in seawater and then undergone further dilution and extensive dispersion ${ }^{1,3}$. On the other hand, the radiocesium that has been deposited in the seafloor off the coast of the FDNPP (down to the depth of $200 \mathrm{~m}$ ) was estimated to account for several percent of the radiocesium released into the ocean or accumulated onshore (ca. $100 \times 10^{12} \mathrm{~Bq}$ or $100 \mathrm{TBq}^{8)}$ ). However, it is of great concern that, along the coast, the seafloor sediment contaminated with the radiocesium poses a risk to organisms that dwell in these waters. In October and November 2015 , over $99.9 \%$ of fishery products were reported to have a radiocesium concentration below the safety threshold of $100 \mathrm{~Bq} \mathrm{~kg}^{-1}$ (Fisheries Agency website: http://www.jfa.maff.go. $\mathrm{jp} / \mathrm{j} / \mathrm{housyanou} / \mathrm{kekka} . \mathrm{html}$ ). Based on an observation and simulation, however, it has been reported that benthic organisms experience a slower reduction in the concentration of radiocesium compared to that in ambient water, and the behavior of radiocesium throughout the food chain is still a matter of argument ${ }^{9)}$. Therefore, quantitative studies are crucial to determining how radioactive cesium is removed from the seafloor sediment.

In this study, the annual total ${ }^{134} \mathrm{Cs}$ flux $\left(={ }^{137} \mathrm{Cs}\right.$ flux $)$ at $1,000 \mathrm{~m}$ over a three-year period was about $70 \mathrm{~Bq} \mathrm{~m}^{-2} \mathrm{yr}^{-1}[(143+30+33) / 3]$ on average. If we suppose that this figure is the average ${ }^{137} \mathrm{Cs}$ flux in semi-pelagic waters (depth: 200 to 1,500 m) off the coast of Fukushima, Miyagi, and Ibaraki $\left(38.5\right.$ to $35.7^{\circ} \mathrm{N}$ ), the annual total amount of radiocesium flux is $1.4 \times 10^{12} \mathrm{~Bq} \mathrm{yr}^{-1}\left(70 \mathrm{~Bq} \mathrm{~m}^{-2} \mathrm{yr}^{-1} \times 2.05 \times 10^{10} \mathrm{~m}^{2}\right)$ or $1.4 \mathrm{TBq} \mathrm{yr}^{-1}$. Moreover, if we assume that this amount of ${ }^{137} \mathrm{Cs}$ is a result of the lateral transport of seafloor sediment from coastal areas shallower than $200 \mathrm{~m}$, the residence time or attenuation time for ${ }^{137} \mathrm{Cs}$ on the seafloor along the coast can be estimated to be roughly 70 years $\left(100 \mathrm{TBq} / 1.4 \mathrm{TBq}^{-1}\right)$. In other 
words, most of the radioactive cesium deposited on the seafloor along the coast remains there, while about 1 to $2 \%$ migrates offshore every year.

As this study demonstrates, time-series sediment traps are an effective tool for the precise detection of the offshore time-series migration of radionuclides over a long period. Meanwhile, the monitoring data obtained from coastal areas demonstrates that the radiocesium concentration in the coastal sediment is decreasing by a few dozen percent every year (Nuclear Regulation Authority: "Results from marine monitoring" (http://radioactivity.nsr.go.jp)), which is in contrast to our estimate of a few percent every year. This faster decrease can be attributed to the compound effect of the lateral transport of the radiocesium to offshore areas as well as the following processes: 1) the radioactive decay of the radiocesium; 2) the dissolution of the radiocesium in seawater ${ }^{10}$; and 3 ) the dilution of the radiocesium from disturbances by benthic organisms (bioturbation) ${ }^{8}$. The most crucial task for further marine surveys is to accurately evaluate the balance of these actions and thereby produce forecasts for the marine environment around Fukushima.

\section{Acknowledgments}

The observation and research work detailed in Reference Document \#6 was conducted using funding provided by the Grants for Rapid Response Research (RAPID) from the US National Science Foundation (NSF), the Strategic International Research Cooperative Program (J-RAPID), and the Interdisciplinary Study on Environmental Transfer of Radionuclides from the Fukushima Daiichi NPP Accident (ISET-R) under the Grant-in-Aid for Scientific Research on Innovative Areas from the Ministry of Education, Culture, Sports, Science and Technology.

\section{References}

1) M. Aoyama et al.: Journal of Oceanography. DOI: 10.1007/s10872-015-0332-2 (2015).

2) S. Yoshida et al.: Geophysical Research Letters, 42, 7139-7147 (2015).

3) M. Aoyama et al.: Journal of Oceanography. DOI: 10.1007/s10872-015-0335-z (2015).

4) M. Honda: Geochemistry [in Japanese], 49, 227-238 (2015).

5) M. Honda et al.: Biogeosciences, 10, 3525-3534 (2013).

6) K.O. Buesseler et al.: Environmental Science and Technology, 49, 9807-9816 (2015).

7) S. Otosaka et al.: Environmental Science and Technology, 48, 12595-12602 (2014).

8) E. Black and K.O. Buesseler: Biogeosciences, 11, 5123-5137 (2014).

9) Y. Tateda et al.: Journal of Environmental Radioactivity, 124, 1-12 (2013).

10) S. Otosaka and T. Kobayashi: Environmental Monitoring Assessment, 185 (7), 5419-5433 (2013). 